\title{
Relationships between mild traumatic brain injury sustained in combat and post-traumatic stress disorder Robert L Ruff ${ }^{1,2,3^{*}}$, Ronald G Riechers $\mathrm{II}^{1,2,3}$ and Suzanne S Ruff ${ }^{3,4}$
}

\author{
Addresses: ${ }^{1}$ Neurology Service, Louis Stokes Cleveland Department of Veterans Affairs Medical Center, Cleveland, Ohio 44106, USA; ${ }^{2}$ Department \\ of Neurology, Case Western Reserve University, Cleveland, Ohio 44106, USA; ${ }^{3}$ Polytrauma Treatment Team, Louis Stokes Cleveland Department of \\ Veterans Affairs Medical Center, Cleveland, Ohio 44106, USA; ${ }^{4}$ Health Psychology Section, Psychology Service, Louis Stokes Cleveland Department \\ of Veterans Affairs Medical Center, Cleveland, Ohio 44106, USA \\ *Corresponding author: Robert L Ruff (robert.ruff1@va.gov) \\ FI000 Medicine Reports 2010, 2:64 (doi:10.3410/M2-64)
}

The electronic version of this article is the complete one and can be found at: http://fl000.com/reports/medicine/content/2/64

\begin{abstract}
The setting of the trauma is a distinguishing feature between mild traumatic brain injury (mTBl; also called concussion) that occurs in civilian settings compared with that occurring in combat. Combat $\mathrm{mTBI}$ is frequently associated with a prolonged stress reaction, post-traumatic stress disorder (PTSD). Individuals with $\mathrm{mTBI}$ and PTSD from combat in Operations Iraqi Freedom and Enduring Freedom often develop prolonged post-concussion symptoms (PCSs) such as headache. Both mTBI and PTSD may contribute to PCSs. PTSD may worsen and prolong the PCSs following mTBI by disrupting sleep. It is not known how mTBI predisposes an individual to develop PTSD.
\end{abstract}

\section{Introduction and context}

Mild traumatic brain injury (mTBI) is common among military personnel and veterans who served in Operations Iraqi Freedom and Enduring Freedom (OIF/OEF). Among soldiers deployed in OIF, $22.8 \%$ had traumatic brain injury (TBI), predominantly mTBI [1]. While there is a general opinion that the prevalence of post-traumatic headaches is higher in association with combat mTBI than with $\mathrm{mTBI}$ sustained in a civilian setting [2], the data are not conclusive. A prospective controlled study of headaches in civilians who had traumatic injury compared 100 sequential patients with mTBI and 100 matched minor injury controls who had non-deceleration injuries; $15 \%$ of those with mTBI had persistent post-traumatic headache at 3 months compared to $2 \%$ of the minor non-TBI injury controls [3]. In contrast, a study of $340 \mathrm{OIF} / \mathrm{OEF}$ veterans found that $55 \%$ of the veterans had headaches when evaluated typically more than a year after the combat TBI [4]. Another study of $155 \mathrm{OIF} / \mathrm{OEF}$ veterans with combat mTBI found that $52 \%$ of the veterans had headaches that persisted for years after the last episode of TBI [5]. The differences in the prevalence of headaches may be partly due to differences in sampling. The veterans in the two prior studies were receiving care from the Department of Veterans Affairs, but not all veterans elect to receive care from the Department of Veterans Affairs. It is possible that the veterans in the prior study represent enriched samples of veterans with medical issues. Therefore, the veteran studies may over-represent the prevalence of headache. In a brigade combat team that was deployed in Iraq for 1 year, $22.8 \%$ of soldiers had a physician-confirmed TBI, usually mTBI [1]. Among the soldiers with TBI, 81.3\% reported headaches immediately after the TBI and 20.3\% reported headaches after the deployment. In another military study of headaches among 5270 soldiers returning from an OIF/OEF deployment, 1033 (19.6\%) had combat concussions, and among the group with mTBI, $97.8 \%$ reported headaches during the last 3 months of their deployment [6]. The differences in prevalence of post-traumatic headaches based upon the first military study - 20.3\% (combat) versus $15 \%$ (civilian) - is not significant, but the headache prevalence of $97.8 \%$ noted in the second study would have significantly exceeded the $15 \%$ prevalence found in civilians. The second study considered all headaches that occurred following TBI, with $42 \%$ of the post-traumatic headaches beginning more 
than 1 month after TBI. Even if one only considered the prevalence of headache that began within 1 month of TBI in this study (57\%), this would still have been significantly greater than the $15 \%$ civilian prevalence $(P<0.001)$. Therefore, due to the variations in the findings of the military studies, it is uncertain whether post-traumatic headaches are more prevalent following combat mTBI.

The study of the brigade combat team revealed that, after deployment, 39\% of soldiers with TBI reported persistent post-concussion symptoms (PCSs) [1] and the military study of 5270 soldiers, also discussed above, found that at least $98 \%$ of soldiers had PCSs in the last 3 months of deployment [6]. Veterans with combat mTBI may have persisting PCSs for several reasons. The US Institute of Medicine recently reported an association between mTBI and the development of post-traumatic stress disorder (PTSD) for OIF/OEF military personnel [2]. Combat TBI occurs in situations likely to induce PTSD and those at risk for combat TBI are often exposed to many other psychologically traumatic events, such as injury or death of fellow soldiers as well as being under constant threat to their own lives [7-9]. Symptoms associated with PTSD overlap with PCSs (Figure 1) so that some PCSs may be due to co-existent PTSD [4,8-10]. Combat mTBI usually does not remove military personnel from combat. Consequently, soldiers with mTBI can be returned quickly to combat stress, which will preclude a rest period that might aid recovery from mTBI [7].

Figure I. Overlap of symptoms associated with mild traumatic brain injury ( $\mathrm{mTBI})$ and post-traumatic stress disorder (PTSD)

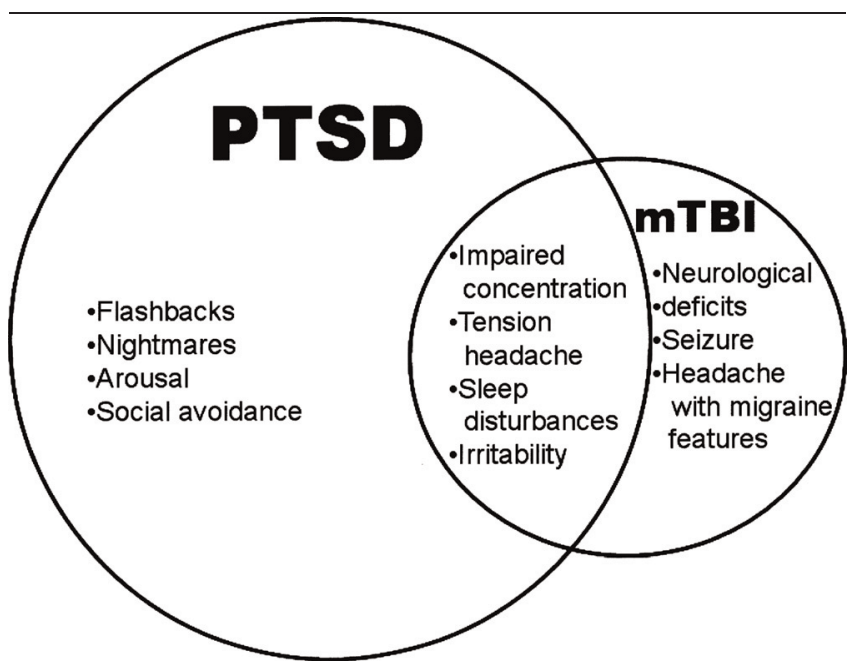

Symptoms that are common to $\mathrm{mTBI}$ and PTSD include impaired concentration, tension headaches, mental slowness, and indecision. Distinct features of PTSD include intrusive flashbacks, recurrent nightmares, hyperarousal, and social avoidance. Distinct features of TBI include neurological deficits, seizures, and headaches with migraine features.
mTBI appears to increase the risk of developing PTSD. In a civilian study, the prevalence of PTSD following mTBI was $6 \%$, which was about 1.9 -fold higher (odds ratio $=$ $1.92,95 \%$ confidence interval $=1.08-3.40$ ) than following trauma without $\mathrm{mTBI}$ [11]. The reported prevalence of PTSD following combat mTBI appears to be greater than after civilian mTBI. About $40 \%$ of military personnel and veterans with combat-acquired mTBI have co-existent PTSD [4,10,12]. Among active duty military personnel deployed in Iraq (OIF) who had an episode of loss of consciousness, $43.9 \%$ had PTSD compared with $16.2 \%$ for soldiers with other injuries and $9.1 \%$ for soldiers with no injury [8]. Another study of 277 OIF/OEF veterans found that $18.8 \%$ had mTBI and that the veterans with $\mathrm{mTBI}$ were more likely to have PTSD than veterans who did not have mTBI [13]. While these findings suggest that mTBI increases the likelihood of PTSD, they do not clarify the mechanisms.

Soldiers with mTBI were more likely to report persisting PCSs than were soldiers with other injuries $[8,13]$. Hoge et al. $[8,14]$ argue that the PCSs are due to PTSD and depression, not mTBI. However, against this argument is the observation that $69 \%$ of veterans with mTBI who have PCSs have neurological abnormalities on clinical examination [5]. In addition, a recent study [15] of OIF/OEF veterans with mTBI who had PCSs (with or without PTSD) reported that they exhibited decreased cerebral metabolic rate of glucose in the cerebellum, pons, and medial temporal lobe. They also had subtle impairments in verbal fluency, cognitive processing speed, attention, and working memory, similar to those reported in the literature for patients with cerebellar lesions. The deficits in cerebellar metabolism and cognitive performance were felt by the authors to be manifestations of brain injury rather than PTSD and the cerebellum has not been noted to be a locus of abnormality in studies of individuals with PTSD without TBI (see below). The presence of abnormalities on neurological examination, brain metabolism, and cognitive testing suggest that veterans with mTBI and PCSs can have persistent brain injury. Therefore, it may be more prudent to consider that both the PTSD and persisting brain injury are contributing to the PCSs. Figure 1 illustrates the overlap of symptoms associated with mTBI and PTSD. Either persisting brain injury or PTSD could produce many of the PCSs.

\section{Recent advances}

Recent imaging studies have identified brain functions or structures associated with mTBI. Abnormalities in white matter can be seen in individuals with mTBI using magnetic resonance imaging techniques such as diffusion tensor imaging. The white matter changes reflect 
axonal injury due to mTBI $[16,17]$. The extent of axonal injury is related to TBI severity, with severe TBI having more extensive axonal injury [18]. Additionally, individuals with mTBI can manifest abnormal foci of neuronal activity or cerebral blood flow. Loci of injury or abnormal cerebral metabolism include the inferior medial frontal lobes, medial temporal lobes, occipital cortex, and cerebellum [7,15,16,19-22].

In individuals without TBI, PTSD is associated with abnormal cerebral activity involving the inferior frontal lobes and anterior medial temporal lobes $[16,20,23,24]$. The areas of abnormal cerebral activity in the frontal and medial temporal lobes seen in PTSD overlap with the loci of injury identified in individuals with mTBI. Therefore, the cerebral injury associated with mTBI may potentiate the development of PTSD in response to a traumatic event.

The likelihood of an individual developing PTSD is influenced by many factors, including the character of the traumatic exposure and the individual's psychological resiliency and educational history [25]. Although the physiological connections between mTBI and the genesis of PTSD have not been elucidated, studies of military combat mTBI $[8,13,26]$ and adult civilian TBI [11] indicate that PTSD is associated with mTBI (Figure 2). A study of civilian children involved in motor vehicle accidents did not find an association between mTBI and PTSD [27]. Cognitive impairment due to TBI may increase the risk for an individual to develop PTSD by compromising their ability to psychologically adjust to a traumatic event [28].

Figure 2. Traumatic brain injury (TBI) may influence the development of post-traumatic stress disorder (PTSD) following a traumatic event

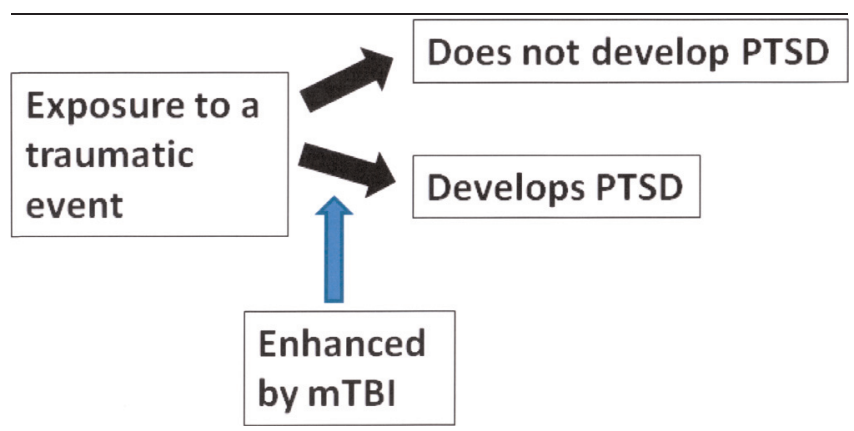

Following a traumatic event, several factors influence whether an individual develops PTSD. TBI may influence the likelihood of an individual developing PTSD following a traumatic event by compromising the ability of an individual to psychologically adjust to a traumatic event. While combat mild TBI appears to increase the likelihood of PTSD developing, severe TBI may reduce the likelihood of PTSD developing.
There are several reasons why mTBI acquired in combat may be more likely to produce longer lasting or more persistent cerebral injury than civilian-acquired mTBI. Military personnel in OIF/OEF often experience multiple mTBI events $[5,7,15,29]$, creating the possibility of accumulation of injury [2,7]. The most common cause for combat mTBI was exposure to an explosion. Combat TBI caused by a blast is often associated with two almost simultaneous traumatic events to the brain. In combat, military personnel are often close enough to an explosion to experience the pressure wave. In addition, military personnel often experience additional head trauma from the explosion due to being thrown by the blast-wind, being impacted by shrapnel, or being involved in a motor vehicle accident associated with the explosion [7].

The PCSs associated with combat mTBI differ from those associated with civilian mTBI. Civilian mTBI is usually associated with tension-type headaches, whereas the headaches reported following combat mTBI are more likely to have migraine features $[5,6,30]$. The co-existence of MTBI and PTSD, which is frequently seen with combat mTBI, appears to increase the severity of PCSs and the number of PCSs that are endorsed [31-33].

Impaired sleep due to PTSD may be partially responsible for the prolonged PCSs. Interrupted sleep due to nightmares is common in veterans with mTBI and PTSD $[29,33]$. Prazosin successfully blocks nightmares and other sleep interruptions caused by PTSD $[34,35]$. In an observational study of OIF/OEF veterans with mTBI due to combat explosions, prazosin treatment combined with sleep hygiene counseling was able to reduce PCS and improve cognitive functioning [29].

\section{Implications for clinical practice}

Combat mTBI is not an isolated condition; it is often associated with PTSD and pain, particularly headaches with migraine features $[4,10]$. It is critical to address the residual brain injury, pain, and psychological manifestations of PTSD. Increasing evidence indicates that impaired sleep will exacerbate pain disorders such as PCSs [36]. Thus, improving sleep may be a good initial step in treating PCSs due to MTBI and PTSD. In the aforementioned observational study, the combination of prazosin and sleep hygiene counseling was highly efficacious and well accepted by OIF/OEF veterans [29].

\section{Abbreviations}

mTBI, mild traumatic brain injury; OIF/OEF, Operations Iraqi Freedom and Enduring Freedom; PCS, postconcussion symptom; PTSD, post-traumatic stress disorder; TBI, traumatic brain injury. 


\section{Competing interests}

The authors declare that they have no competing interests.

\section{Acknowledgments}

The authors are supported by the Department of Veterans Affairs and the National Institutes of Health.

\section{References}

I. Terrio H, Brenner LA, Ivins BJ, Cho JM, Helmick K, Schwab K, Scally $K$, Bretthauer $R$, Warden $D$ : Traumatic brain injury screening: preliminary findings in a US army brigade combat team. J Head Trauma Rehabil 2009, 24:14-23.

2. Ishibe N, Wlordarczyk RC, Fulco C: Overview of the Institute of Medicine's Committee search strategy and review process for Gulf War and health: long-term consequences of traumatic brain injury. J Head Trauma Rehabil 2009, 24:424-29.

3. Faux S, Sheedy J: A prospective controlled study in the prevalence of posttraumatic headache following mild traumatic brain injury. Pain Med 2008, 9:100I-II.

4. Lew HL, Otis JD, Tun C, Kerns RD, Clark ME, Cifu DX: Prevalence of chronic pain, posttraumatic stress disorder, and persistent postconcussive symptoms in OIF/OEF veterans: Polytrauma clinical triad. J Rehab Res Devel 2009, 46:697-702.

FI000 Factor 6.0 Must Read

Evaluated by Robert Ruff 13 Jan 2010

5. Ruff RL, Ruff SS, Wang X-F: Headaches among veterans of Operations Iraqi Freedom and Enduring Freedom with mild traumatic brain injury associated with exposures to explosions. J Rehabil Res Dev 2008, 45:941-53.

6. Theeler BJ, Flynn FG, Erickson JC: Headaches after concussion in US soldiers returning from Iraq or Afghanistan. Headache 2010, [Epub ahead of print].

7. Benzinger TLS, Brody D, Cardin S, Curley KC, Mark A, Mintun MA, Mun SK, Wong $\mathrm{KH}$, Wrathall JR: Blast-related brain injury: imaging for clinical and research applications: report of the 2008 St. Louis Workshop. J Neurotrauma 2009, 26:2 1 27-44.

8. Hoge CW, McGurk D, Thomas JL, Cox AL, Engel CC, Castro CA: Mild traumatic brain injury in U.S. soldiers returning from Iraq. N Engl J Med 2008, 358:453-63.

FI000 Factor 6.4 Must Read

Evaluated by Robert Ruff 18 Mar 2008, Philippe Azouvi 10 Jun 2009

9. Vanderploeg RD, Belanger HG, Curtiss G: Mild traumatic brain injury and posttraumatic stress disorder and their associations with health symptoms. Arch Phys Med Rehabil 2009, 90:1084-93.

10. Gironda RJ, Clark ME, Ruff RL, Chait S, Craine M, Walker R, Scholten J: Traumatic brain injury, polytrauma, and pain: challenges and treatment strategies for the Polytrauma Rehabilitation Network. Rehabil Psychol 2009, 54:247-58.

II. Bryant RA, O'Donnell ML, Creamer M, McFarlane AC, Clark CR, Silove D: The psychiatric sequelae of traumatic injury. $A m$ J Psychiatry 2010, 167:312-20.

12. Carlson K, Kehle S, Meis L, Greer N, MacDonald R, Rutks I, Wilt TJ: The Assessment and Treatment of Individuals with History of Traumatic Brain Injury and Post-Traumatic Stress Disorder: A Systematic Review of the Evidence. Washington DC: Department of Veterans Affairs Health Services Research and Development Service, 2009:72.

13. Pietrzak RH, Johnson DC, Goldstein MB, Malley JC, Southwick SM: Posttraumatic stress disorder mediates the relationship between mild traumatic brain injury and health and psychosocial functioning in veterans of Operations Enduring Freedom and Iraqi Freedom. J Nerv Ment Dis 2009, 197:748-53.

14. Hoge CW, Goldberg HM, Castro CA: Care of war veterans with mild traumatic brain injury - flawed perspectives. $N$ Engl J Med 2009, 360:|588-9|.
15. Peskind ER, Petrie EC, Cross DJ, Pagulayan K, McCraw K, Hoff D, Hart K, Yu C-E, Raskind MA, Cook DG, Minoshima S: Cerebrocerebellar hypometabolism associated with repetitive blast exposure mild traumatic brain injury in 12 veterans with persistent post-concussive symptoms. Neurolmage 2010, [Epub ahead of print].

16. Van Boven RW, Harrington GS, Hackney DB, Ebel A, Gauger G, Bremner D, D'Esposito M, Detre JA, Haacke M, Jack CR, Jagust WJ, Le Bihan D, Mathis CA, Mueller S, Mukherjee P, Schuff N, Chen A, Weiner MW: Advances in neuroimaging of traumatic brain injury and posttraumatic stress disorder. J Rehab Res Dev 2009, 46:717-56.

FI000 Factor 3.0 Recommended

Evaluated by Robert Ruff 06 Jan 2010

I7. Mayer AR, Ling J, Mannell MV, Gasparovic C, Phillips JP, Doezema D, Reichard R, Yeo RA: A prospective diffusion tensor imaging study in mild traumatic brain injury. Neurology 2010, 74:643-50.

18. Kraus MF, Susmaras T, Caughlin BP, Walker CJ, Sweeney JA, Little DM: White matter integrity and cognition in chronic traumatic brain injury: a diffusion tensor imaging study. Brain 2007, I30:2508-19.

19. Topal NB, Hakyemez B, Erdogan C, Bulut M, Koksal O, Akkose S, Dogan S, Parlak M, Ozguc H, Korfali E: MR imaging in the detection of diffuse axonal injury with mild traumatic brain injury. Neurol Res 2008, 30:974-78.

20. Brenner LA, Ladley-O'Brien SE, Harwood JE, Filley CM, Kelly JP, Homaifar BY, Adler LE: An exploratory study of neuroimaging, neurologic, and neuropsychological findings in veterans with traumatic brain injury and/or posttraumatic stress disorder. Mil Med 2009, I 74:347-52.

21. Lo C, Shifteh K, Gold T, Bello JA, Lipton ML: Diffusion tensor imaging abnormalities in patients with mild traumatic brain injury and neurocognitive impairment. J Comput Assist Tomogr 2009, 33:293-97.

22. Huang M-X, Theilmann RJ, Robb A, Angeles A, Nichols S, Drake A, D'Andrea J, Levy M, Holland M, Song T, Ge S, Hwang E, Yoo K, Cui L, Baker DG, Trauner D, Coimbra R, Lee RR: Integrated imaging approach with MEG and DTI to detect mild traumatic brain injury in military and civilian patients. J Neurotrauma 2009, 26:1213-26.

23. Whalley MG, Rugg MD, Smith AP, Dolan RJ, Brewin CR: Incidental retrieval of emotional contexts in post-traumatic stress disorder and depression: an fMRI study. Brain Cogn 2009, 69:98-107.

24. Sailer U, Robinson S, Fischmeister FP, König D, Oppenauer C, LuegerSchuster B, Moser E, Kryspin-Exner I, Bauer H: Altered reward processing in the nucleus accumbens and mesial prefrontal cortex of patients with posttraumatic stress disorder. Neuropsychologia 2008, 46:2836-44.

25. Pietrzak RH, Johnson DC, Goldstein MB, Malley JC, Southwick SM: Psychological resilience and postdeployment social support protect against traumatic stress and depressive symptoms in soldiers returning from Operations Enduring Freedom and Iraqi Freedom. Depress Anxiety 2009, 26:745-5I.

26. Hesdorffer DC, Rauch SL, Tamminga CA: Long-term psychiatric outcomes following traumatic brain injury: a review of the literature. J Head Trauma Rehabil 2009, 24:452-59.

27. Mather FJ, Tate RL, Hannan TJ: Post-traumatic stress disorder in children following road traffic accidents: a comparison of those with and without mild traumatic brain injury. Brain Inj 2003, I7:1077-87.

28. Stein MB, McAllister TW: Exploring the convergence of posttraumatic stress disorder and mild traumatic brain injury. Am J Psychiatry 2009, I66:768-76.

29. Ruff RL, Ruff SS, Wang X-F: Improving sleep: Initial headache treatment in OIF/OEF veterans with blast-induced mild TBI. J Rehabil Res Dev 2009, 46:1071-84.

30. Theeler BJ, Erickson JC: Mild head trauma and chronic headaches in returning US soldiers. Headache 2009, 49:529-34. 
31. Broomhall LG, Clark CR, McFarlane AC, O'Donnell M, Bryant R, Creamer M, Silove D: Early stage assessment and course of acute stress disorder after mild traumatic brain injury. I Nerv Ment Dis 2009, 197:178-81.

32. Nelson LA, Yoash-Gantz RE, Pickett TC, Campbell TA: Relationship between processing speed and executive functioning performance among OEF/OIF veterans: implications for postdeployment rehabilitation. J Head Trauma Rehabil 2009, 24:32-40.

33. Belanger HG, Kretzmer T, Vanderploeg RD, French LM: Symptom complaints following combat-related traumatic brain injury: relationship to traumatic brain injury severity and posttraumatic stress disorder. J Int Neuropsychol Soc 2010, 16:194-99.

34. Raskind MA, Peskind ER, Hoff DJ, Hart KL, Holmes HA, Warren D, Shofer J, O'Connell J, Taylor F, Gross C, Rohde K, McFall ME:
A parallel group placebo controlled study of prazosin for trauma nightmares and sleep disturbance in combat veterans with post-traumatic stress disorder. Biol Psychiatry 2007, 6I:928-34.

35. Taylor FB, Martin P, Thompson C, Williams J, Mellman TA, Gross C, Peskind ER, Raskind MA: Prazosin effects on objective sleep measures and clinical symptoms in civilian trauma posttraumatic stress disorder: a placebo-controlled study. Biol Psychiatry 2008, 63:629-32.

36. Fishbain DA, Cole B, Lewis JE, Gao J: What is the evidence for chronic pain being etiologically associated with the DSM-IV category of sleep disorder due to a general medical condition? A structured evidence-based review. Pain Med 2010, II:I58-79. 